\title{
Is Complicated Birth One of the Early Childhood Traumas? A Framework for Birthing Trauma, Its Impacts, and Proliferation*
}

\author{
Ibrahim A. Kira ${ }^{1,2}$, Linda Lewandowski ${ }^{3}$, Lisa Chiodo ${ }^{3}$, Andreas Laddis ${ }^{4}$ \\ ${ }^{1}$ Center for Cumulative Trauma Studies, Stone Mountain, GA, USA \\ ${ }^{2}$ Center for the Study of Stress Trauma and Resiliency, Georgia State University, Atlanta, USA \\ ${ }^{3}$ University of Massachusetts, Amherst, MA, USA \\ ${ }^{4}$ School of Public Health, Boston University, Boston, MA, USA \\ Email: kiraaref@aol.com
}

Received 22 February 2016; accepted 27 March 2016; published 30 March 2016

Copyright (C) 2016 by authors and Scientific Research Publishing Inc.

This work is licensed under the Creative Commons Attribution International License (CC BY). http://creativecommons.org/licenses/by/4.0/

c) (i) Open Access

\section{Abstract}

Objective: Birthing trauma (BT) (i.e., complicated birth) is an early life complex trauma for the baby and mother that never been empirically examined or considered within the trauma field as a traumatic stressor for the newborn. The goal of current study is to examine its effects on mental health and neurocognitive functioning and explore its proliferation to other life traumas. Method: Current study utilizes a novel developmental-based trauma framework (DBTF) to empirically test assumptions about some of its negative delayed psychosocial and neurocognitive effects in adolescents, and the dynamics of its proliferation to other potentially dependent traumas. A community sample of 410 African American and Iraqi adolescents have been administered measures of traumas (CTS), birthing trauma, PTSD, complex PTSD (CTD), existential anxiety and WISC IV. We controlled for the numerous cumulative stressors and traumas that could potentially be playing a role. .Results: Correlations and path analyses and multigroup invariance found that BT predicted elevated symptoms of post-trauma spectrum disorders, reduced IQ scores, and increased discrepancy IQ index. These relationships were strongly invariant across gender and cultural groups. BT directly predicted other early childhood traumas, and indirectly all other life trauma types, which support BT proliferation hypothesis. These relationships were strongly invariant across gender. Conclusion: Screening for Birthing Trauma as one of the serious early childhood trauma is important. Early intervention with BT victims to provide early psychological and educational help and prevent proliferation dynamics is important.

*This article is based on a paper accepted for presentation in the American Psychological Association Annual Convention, Denver, Colorado and August, 2016.

How to cite this paper: Kira, I. A., Lewandowski, L., Chiodo, L., \& Laddis, A. (2016). Is Complicated Birth One of the Early Childhood Traumas? A Framework for Birthing Trauma, Its Impacts, and Proliferation. Psychology, 7, 426-443. 


\section{Keywords}

\section{Early Childhood Traumas, Developmentally-Based Trauma Framework (DBTF), Neurocognitive Functioning, Trauma Proliferation, Existential Annihilation Anxiety}

\section{Introduction}

Aging and birthing are objective developmental events or sequence of events that entail or project the start or end of a person's life which are potentially stressful, sometimes traumatizing and parts of growing up sequelae. However, such stressful developmental landmarks are controversial concerning its potential physical and mental health effects. For Rank, 1924, birth is the primal anxiety that consists of violent expulsion from the blissful intrauterine state-separation from the mother-and the threat with asphyxia along the way, which make it inevitably traumatic. The regular birth was suggested, from this psychoanalytic perspective to be the first trauma for the newborn. Research suggested that about one-third of women experience stressful labor and delivery that they view as traumatic (Creedy, Shochet, \& Horsfall, 2000; Soet, Brack, \& Dilorio, 2003). Further, childbirthrelated PTSD has been diagnosed in women who do not describe their labor and delivery as traumatic (Soet et al., 2003). For long, complicated birth, however, was never discussed as an early physical and psychological trauma for the newborn. While normal birth can be extremely stressful for women, different types of complicated births can be life-threatening to the mother and to the baby and qualify as traumatic stress for both. Rates of PTSD for the mother at 3 to 6 weeks postpartum range from 0.8\% (Ford, Ayers, \& Bradley, 2010) to 4.6\% (Creedy et al., 2000), to 9\% (Beck, Gable, Sakala, \& Declercq 2011). Another 18.5\% (Onoye, Goebert, Morland, Matsu, \& Wright, 2009) to 30.0\% of mothers (Soet et al., 2003) endorse subsyndromal posttraumatic stress symptoms during this time period (for meta-analysis, see: Grekin \& O’Hara, 2014). For example, several studies have found an association between maternal and infant complications and later posttraumatic stress symptoms (e.g., Beck 2010; De Schepper et al., 2016; Edworthy, Chasey, \& Williams, 2008; Halperin, Sarid, \& Cwikel, 2015). Specifically, elevated rates of posttraumatic stress symptoms and depression have been documented in mothers of premature infants (Misund, Nerdrum, Bråten, Pripp, \& Diseth, 2013; White, Matthey, Boyd, \& Barnett, 2006), women who underwent emergency cesarean section (Callahan \& Hynan, 2002; Creedy et al., 2000), and women whose physicians used forceps during the delivery (Creedy et al., 2000). Women who experience a difficult childbirth are at an increased likelihood of experiencing symptoms of postpartum depression, state anxiety, and perceived stress and of engaging in binge drinking (Onoye et al., 2009; Iles, Slade, \& Spiby, 2011).

PTSD and depression following difficult birth put women at high risk of impairment in their relationships with their infants, which could in turn foster insecure attachment style in the baby (Bailham \& Joseph, 2003; Ross \& McLean, 2006; Parfitt \& Ayers, 2009; Forcada-Guex, Borghini, Pierrehumbert, Ansermet, \& MullerNix, 2011).

Complicated birth is a trauma for the mother and for the newborn and has potentially significant lasting effects on both. While the traumatic effects of birthing trauma on the mother, the fully developmentally mature adult, are well documented and are associated with increased PTSD and depression, there are almost no studies on its psychological and cognitive effects, as a primary developmental trauma on the child. Given the existential importance of birth and the potential threat of BT to the mere existence of the baby and the mother, birthing trauma can be conceived as primal existential threat potentially yielding existential and annihilation anxieties. That may involve a no-exit existential crisis for both the baby and the mother.

For the child who realizes, from what have been told by adults, that his/her mere existence was at risk from the start, it is safe to assume that his existential anxieties would be higher, inducing alterations in threat perception, making her/him more emotionally vulnerable. Existential anxiety found to be associated with an increase in different mental health symptoms (e.g., Kira, Templin et al., 2012). In addition to severe physical pain and potentially existential threat, the newborn suffers profound nervous and emotional shocks, which are concomitants of every difficult birth experience. Further, recent evidence suggests that the HPA axis, which is associated with increased risk for negative mental health outcomes, is more susceptible to developing acute dysregulation when exposed to trauma during infancy (Kuhlman, Vargas, Geiss, \& Lopez-Duran, 2015).

Three pathways or trajectories may be in operation in birthing trauma. The first may start through the direct 
experience of extreme pain and the direct existential threat that has associative conditioning and memory traces and dynamics and can be recorded or registered as rudimentary implicit memories (e.g., Li, Callaghan, \& Richardson, 2014). The infant brain selectively registers only the event that has a more instrumental value that tunes up or down the affective and emotion regulation system and may create implicit triggers of unrecognized feelings. Victims of complicated birth may have implicit pre-verbal memories resulting from the experience. Due to the nonverbal nature of schemas of pre-verbal events, it is registered as experiential/emotional and implicit rather than cognitive or explicit schemas. Infants do not think but they do process emotions and long-term memories are stored as affective schemas that have unique qualities (Gaensbauer, 2002). "It is difficult or impossible for children to map newly acquired verbal skills on to the existing preverbal memory representations" (Richardson, \& Hayne, 2007). They can have troubling memories that they cannot identify in words. This means that they cannot understand what they are feeling. This may lead to a cognitive emotional disconnection. Children fail to translate their preverbal memories into the language (Simcock, Hayne, 2002). Preverbal and implicit negative memories can inhibit the establishment of future attachments. The second trajectory is through mother's or parents' narrative about the events that validate or invalidate his/her residual implicit memory traces and modulates his/her appraisal/reappraisal of the event. Both trajectories may contribute to tuning up or down the affective system producing either restricted mood or heightened arousal and fear conditioning. Independent from memory systems and childhood amnesia, recent studies found that early life stress produces a persistent impact on cognition, which is independent of the memory of early life events (e.g., Quinn, Skipper, \& Claflin, 2013), which may suggest that a pre-cognitive conditioning system may be at work. The third trajectory is initiated through mother's mental health. Mother's post-partum depression or PTSD due the difficult childbirth impacts how she interacts with her baby and can directly impair mother-infant attachment because it impairs her ability to deliver responsive care.

Chronic and acute exposures to stress have physiological and psychological consequences, whether it occurs during the natal period, infancy, childhood, adolescence, adulthood or aging (e.g., Lupien, McEwen, Gunnar, \& Heim, 2009). Early childhood trauma affects negatively child development and has been associated with alteration in the brain structures and functions and reduced size of the amygdala, hippocampus and prefrontal cortex (e.g., Daniels, Lamke, Gaebler, Walter, \& Scheel, 2013). These areas are responsible for many complex functions including memory, attention, perceptual awareness, thinking, language, and consciousness. These changes may negatively affect IQ and the ability to regulate emotions (National Scientific Council on the Developing Child, 2005/2014) However, their specific effects on the brain, cognition and interpersonal and social behavior emerge as a function of the timing, duration and severity of the exposure, and the maturation and developmental processes of attachment/separation and identity (personal, role, and collective) formation and interdependence across life span. Further, such early life adversities induce epigenetic modulation of gene expression that results in altered adult phenotypes and increased vulnerability to illness (e.g., De Bellis \& Zisk, 2014; Labonte et al., 2012, McGowan, 2013).

It is a salient assumption in the trauma field that the earlier the trauma, the worse potential negative effects are expected (e.g., Ogle, Rubin, Berntsen, \& Siegler, 2013; Ogle, Rubin, \& Siegler, 2013). Birthing trauma (BT) is one of the earliest childhood traumas that highlight the start of life itself with severe pain and adversities. However, BTs have different characteristics that make its potential post-traumatic symptoms unique and different from typical PTSD symptoms, as the memory, or even traces of it, may not be evident to produce memory intrusion/re-experiencing which is one of the hallmarks of PTSD symptoms and diagnosis. However, re-experiencing and avoidance may be still deeply implicit. Other DSM-V diagnosis of "other specified trauma and stress related disorder" (309.89) may be more applicable.

BT framework fits well within the developmentally-based trauma framework (DBTF) (e.g., Kira, 2001, 2004, 2010; Kira et al., 2008, Kira, Fawzi, \& Fawzi, 2013, Kira, Ashby, Lewandowski et al., 2013; Kira, Alawneh, Aboumediene, Lewandowski, \& Laddis, 2014; Kira, Lewandowski, Chiodo, \& Ibrahim, 2014; Kira, Omidy, \& Ashby, 2014; Kira, Omidy, Fawzi et al, 2015). BT is one of the early developmental traumas that precedes and may have the comparable impact of early attachment trauma, e.g., attachment disruptions and abandonment by primary caregivers (e.g., Bowlby, 1988) for 0 - 3 years of age. Further, it may affect the quality of attachment as we discussed and will discuss and explore further. The developmental timing of the traumatic exposure, e.g., in the uterus, birthing, attachment through 0 - 3, sexual abuse and neglect of a child, play differential roles in the severity of their initial, subsequent and delayed negative psychosocial and neuro-cognitive effects. While trauma in the pre-natal stage is still controversial, birthing trauma (i.e., complicated birth) is the first traumatic expe- 
rience that the newborn may face in the natal stage, and thus has possible stronger negative effects in shaping his/her responses to life adversities, his/her attachment capacities and to other subsequent traumas and development.

The effects of internal sufferings (e.g., severe pain related to life-threatening health conditions, or complicated birth) or external sufferings (e.g., severe pain caused by torture, or assault, or by induced or difficult labor in this case) on the different integrated systems of human organism, e.g., biological, physiological, psychological, social and ecological) all may play out in BT. Their effects can spread from each system to the others in real-time and/or on delayed fashion according to the developmental trajectory of each system and across the life span. The interdisciplinary study of trauma that looks at the integrated systems of the human organism should give us a better understanding of the dynamics of internal and external traumatic and chronic stressors of BT, as well as in other trauma types, and of their trajectories across systems.

Additionally, and more importantly, such early traumas that are associated with existential threats, proliferate (for trauma proliferation and stress generation dynamics see Kira, Ashby et al., 2013; Pearlin, Aneshensel, \& Leblanc, 1997) to other dependent subsequent traumas in life. Such proliferation dynamics has been rarely investigated and were not in the focus of most research projects in trauma. Trauma proliferation dynamics may explain a great part of the extended effects of BT. Trauma proliferation theory (Pearlin, Aneshensel, \& Leblanc, 1997), and its recent extensions (Kira, Ashby et al., 2013) analyzes the phenomena of the tendency of stressors to beget stressors and highlights a class of independent traumas (Independent traumas are those that happen out of the individual control, e.g., birthing trauma), that tend to generate dependent stressors that the individual controls (e.g., those related to interpersonal relationship, for example, targeted aggression, avoidance or withdrawals). Independent traumas and stressors spill over to subsequent and dependent traumas. Such proliferation dynamics are especially more represented in the early childhood traumas. For example, birthing trauma can trigger the emergence of a cascade of subsequent serious limitations (e.g., restricted mood and reduced capacity for attachment resulted from BT for the child and postpartum depression and PTSD for the mother), which can negatively affect the quality of attachment with care-giver and trigger in turn sequelae of attachment related disorders.

Two important mechanisms of traumatic stress proliferation may be involved. First, such independent traumas may contribute to subsequent traumas, such as attachment trauma that may trigger (for example) reactive attachment disorder. Second, they may increase the individual vulnerability and susceptibility to victimization, (e.g., for physical and sexual abuse). Stress generation theory proposes that independent life stressors increase an individual's susceptibility to dysfunctional cognitions, attitudes, and behavioral patterns that persist and are, in turn, associated with greater likelihood of subsequent dependent stressors (for a review see Liu, 2013, see also, Kira, 2004; Kira, Fawzi, \& Fawzi, 2013; Kira, Ashby et al., 2013). Integrative models of multiple risk factors that may mediate the relationship between independent and dependent stressors provide amore comprehensive understanding of stress generation (Liu, 2013).

To conclude, BT is severe early physical/medical trauma that may have direct as well as delayed psychological and developmental negative effects. While the traumatic effects of birthing trauma (BT) on the mother, the fully developmentally mature adult, are well researched (e.g., Beck, 2010; Edworthy, Chasey, \& Williams, 2008), there are almost no studies on its psychological and cognitive impact, as primary developmental trauma for the newborn.

No empirical studies examining the proliferation dynamics in BT (or even for any other trauma types with some exceptions), or the association between BT, as traumatic event, and mental health and neurocognitive functioning (e.g., IQ expression or suppression, or on IQ discrepancy indexes) in any of minority and nonminority adolescents were found. The goal of this paper is to empirically test the discussed assumptions of BT theory, and to explore some the delayed psycho-social effects of birthing trauma with its initial physiological and medical traumas, on adolescents and to check the validity of DBTF framework on BT.

\section{Hypotheses}

1) Birthing trauma (BT) as indicated by having told by parents that he/she had a complicated birth predicts existential anxiety and post-trauma spectrum disorders in adolescents. Further, BT predicts neurocognitive deficits as indicated by decreased IQ factors and high discrepancy index between verbal comprehension and perceptual reasoning.

2) Following the Trauma proliferation hypotheses, birthing trauma as independent first trauma in life prolife- 
rates to all other life traumas, especially childhood traumas (abandonment and personal identity trauma (sexual and physical abuse). Birthing trauma is principal vulnerability to such traumas.

3) The two models: the model of the BT negative neurocognitive and mental health effects and the model of BT trauma proliferation are invariant in gender (males and females) and cultural (Iraqi refugee and African American Adolescents) groups, at least on the configural level.

\section{Methods}

\subsection{Procedure}

Adolescent participants from two highly traumatized populations (African-American adolescents [AAAs] and Iraqi refugee adolescents [IRAs] in Detroit and Dearborn, MI) were recruited for study participation. The high trauma load and high PTSD epidemiology (9\% among IRAs and 10\% among AAAs in the current sample, compared to $2 \%-4 \%$ of adolescents in the general population (Ollendick, \& March, 2004) and the different trauma profiles make the combination of the two populations, with large variance of trauma type, ideal for testing the study hypotheses. Approval for this study was obtained from the Human Investigation Committee at Wayne State University (WSU). After complete description of the study to the subjects and their parents, written informed parental consent, and adolescent assent was obtained. IRAs were recruited through an Arab community center in Dearborn, Michigan. Bilingual Arabic research assistant graduate students facilitated the recruitment of subjects who met the age (12 to 18 years old), ethnic (adequate sample size of Iraqi refugee adolescents), and gender distribution criteria (equal representation of gender) set by the research team. AAAs were recruited through churches in Detroit, MI using similar criteria as well as through African-American graduate students. A snowballing technique was utilized in the recruitment process for both. Snowballing technique is usually utilized in sampling rare populations when no sufficient statistical information is available (e.g., Kalton \& Anderson, 1986). Between 100 - 120 students on each of 4 testing days were divided into five girl groups and five boys groups for a total of 10 groups. These 10 groups rotated between five testing stations for a 5-hr day of data collection interspersed with health teaching, crafts, games, prizes, and magic show at lunchtime. The process took place on four weekend days during the months of September, October, and November 2006, at WSU. Interviews were conducted one on one in rooms that allow complete privacy. IQ testing was also completed individually by a certified school psychologist or an educational psychology graduate student. PTSD and trauma interviews were conducted by licensed mental health professionals. Transportation was provided for participants both to and from WSU.

\subsection{Participants}

Total participants included in the analysis were 410 students from grades 5 - 12, age range between 11 - 18 years, (M 13.56, SD 1.49) with 45.6\% ages 11 - 13 years, and 54.6\% ages 14 - 18 years. It included 52\% IRAs and 47\% AAAs, and $46.4 \%$ males and 53.6\% females. Whereas English was the first language spoken at home for AAAs, Arabic was the first language spoken at home by $85 \%$ and English for $15 \%$ for IRAs. Whereas $95 \%$ of AAAs were of various Christian denominations, 97\% of IRAs were Shiite Muslims, 1.7\% were Muslim Sunni, and $1.1 \%$ were Christians. For the IRA group, $85 \%$ have lived in the US 5 or more years, $9 \%$ have lived at least 3 - 4 years in the US and 6\% were US-born to Iraqi refugee parents.

\section{Measures}

\subsection{Cumulative Trauma Scale (CTS)}

The CTS is a 61-item scale that assessed Cumulative Stress. Each item describes an extremely stressful event. The participant was asked to report first if s/he experienced the event, how many times s/he experienced the event, how old they were the first time the event occurred, and how much it affected him/her (positively or negatively on a scale from 0 - 3 for each). "I was led to sexual contact by someone older than me" is an example of the questions that was included. The CTS provides two CT dose measures (1) occurrence and (2) frequency), and two appraisal subscales (negative and positive appraisal). The CTS has been used previously with different clinical and community populations of adults and children (Kira, 2001; Kira et al., 2008). Adequate internal consistency reliability has been reported (range .70 - .89) and good construct and predictive validity have also been reported (Kira et al., 2008). For the purpose of this study, we focused solely on cumulative trauma occur- 
rence for total and for six of the trauma types. The six trauma types include: attachment trauma, for example, parental abandonment; personal identity trauma, for example, sexual abuse, physical abuse, rape, robbed, or mugged; collective identity trauma, for example, oppression, discrimination; survival trauma, for example, shot at or stabbed; family secondary trauma, for example, parents' divorce, parental involvement in combat/war; secondary trauma in the community, for example, witnessing or hearing about others traumas. We used also selected single traumas that represent each type: sexual abuse, abandonment by mother and abandonment by the father, parents' divorce, one of the parents was veterans, oppression/discrimination, and being shot or stabbed. The occurrence measure, in the current study, has adequate alpha reliability (.78), which is good for scales with binary response to questions that ask about events.

\subsection{Birthing Trauma Scale}

A single item that asks about the fact if the person has been told by parents or others that his/her birth was a complicated birth. The answer was coded no (0), not sure (1), or yes (2).

\subsection{Annihilation (Existential) Anxiety Scale (AA)}

Annihilation (Existential) Anxiety Scale (AA) (Kira, Templin, Lewandowski, Ramaswamy et al., 2012) is based on the assumption that there are at least three main sources of the emergence of annihilation threats: personal identity, collective identity, and threats from severe societal structural inequalities. Three items that represent the three components were used, for example, "because of what has happened to me personally or is happening to me personally, I sometimes worry that I just lose my sense of self (I worry that I will cease to exist as an individual person).” The answer was structured on a 5 point-Likert-scale (5. Strongly Agree; 4. Agree; 3. Not Sure; 2. Disagree; 1 . Strongly Disagree). The 3-item scale has been previously used on Iraqi refugees in Michigan and on three samples of Palestinians adults and adolescents, as well in the initial validation study on mental health clients $(\mathrm{N}=399)$. In the initial validation study, and following studies, its alpha reliability ranged between .90 - .95, and its convergent, discriminant and predictive validity was adequate (Kira et al., 2012). Similar results were found in subsequent studies on Palestinian adolescents and adults (Kira, Ashby, Lewandowski et al., 2013). It has an alpha of .93 in the current study.

\subsection{Cumulative Trauma Related Disorders Measure (CTD) (or Complex PTSD) (Kira, Templin, Lewandowski, Ashby et al., 2012)}

This 15 item measure has been developed on five community and clinic samples of adults, adolescent Arab and African Americans. It is an index measure that covers 13 symptom categories: depression, anxiety, somatization, dissociation, auditory and visual hallucinations, avoidance of being with people, paranoid ideations, concentration and memory deficits, loss of self-control, feeling suicidal, and feeling like hurting self. Exploratory and confirmatory factor analysis found four factors (four sub-scales): Executive function deficits and loss of control, suicidality, dissociation/psychosis, and depression/anxiety/somatization comorbidity (Kira, Templin, \& Lewandowski, Ashby et al., 2012). It has good reliability (ranged from .85 and .98). Test-retest reliability in a 6-week interval was .76. The measure has good concurrent, discriminant and predictive validity. Different kinds of traumas, and cumulative trauma "in general" accounted for significant variance as predictors of CTD symptoms. In previous studies, it was highly associated with comorbidity of mental disorders. In the current data, its alpha was .91 and $.95, .97, .98$, and .96 respectively for its sub-scales.

\subsection{Clinician-Administered PTSD Scale CAPS-2 PTSD Measure}

(CAPS-2) (18 items): This measure was developed by Blake et al. (1990) and is widely used to assess PTSD. It is a structured clinical interview that assesses 17 symptoms rated on frequency and severity on a 5-point scale. CAPS demonstrated high reliability with a range from .92 - .99 and showed good convergent and discriminant validity (Weathers, Keane, \& Davidson, 2001). In this study, we used the frequency subscale of CAPS-2 that is currently widely used in psychiatric literature and is highly correlated with the total scale. The scale in the current study has high reliability with an alpha of .97. The scale has four-factor subscales:re-experiencing, avoidance, arousal, and emotional numbness/detachment or dissociation (Palmieri, Weathers, Difede, \& King, 2007). We use the term "dissociation" interchangeably with emotional numbness for the last subscale. Reliability of the four subscales in our sample are adequate to high (alphas were $.96, .92, .89$, and .85, respectively). 


\subsection{WISC IV}

To assess IQ, the Wechsler Intelligence Scale for Children—Fourth Edition (Wechsler, 2003) was completed. The WISC-IV contains 10 core and five supplemental subtests and provides four index scores as well as a single overall score (Full-Scale IQ [FSIQ]) that represents general intellectual ability. The WISC-IV was standardized on a nationally representative sample of 2,200 children aged 6-16 years, closely approximating the 2000 United States Census on sex, race, parent education level, and geographic region. The WISC-IV has 10 core subtests (M $=10, \mathrm{SD}=3$ ) that form four factor indices $(\mathrm{M}=100, \mathrm{SD}=15)$ : verbal comprehension $(\mathrm{VC})$, perceptual reasoning (PR), working memory (WM), and processing speed (PS). The FSIQ $(M=100, S D=15)$ is based on the sum of scores from the 10 core subtests. This four-factor structure was verified by Wechsler with extensive exploratory and confirmatory factor analyses.

The measures utilized in the current study have been previously used and tested on Iraqi refugees in English and Arabic, with adolescents in schools and mental health clinics and proved to have high reliability and validity with this population (e.g., Kira et al., 2006; Kira et al., 2007).

\section{Analysis}

We conducted initial zero-order correlations between birthing trauma, other trauma types, cumulative trauma, mental health variables (PTSD, CTD, and AA), IQ variables and discrepancy index between verbal comprehension and perceptual reasoning. We compared the current associations with the association of the same variables utilized in our previous studies that utilized the trauma, birthing trauma and similar outcome measures (Kira, Lewandowski et al., 2014; Kira, Ashby et al, 2013; Kira, Templin et al., 2011) (from center of cumulative trauma database) on Palestinians adolescents, and adult mental health clients in the USA (details are available in supplementary files). Using Path analysis, we tested different plausible mediation models utilizing AMOS 22.0 (Arbuckle, 2006) to examine the direct and indirect effects (mediated effects) of birthing trauma. To disentangle the effects of BT from other life traumas that happened after traumatic birth and control for their effects we entered other cumulative life trauma along with BT as predictor variables and mental health and IQ and discrepancy variables as dependent and mediating/moderating variables. Further, we tested another path model to check the trauma proliferation hypothesis with birthing trauma as independent variables and all other trauma types (attachment, personal identity, collective identity trauma, role identity (achievement), family, survival and interdependence traumas) as dependent and/or mediating variables. We used bootstrap with bias-corrected confidence intervals to test the significance of the direct and indirect effects of each variable in the model. Bootstrapping is a computer-intensive resampling technique. It involves generating bootstrap samples based on the original observations. When normality assumptions are violated, bootstrapping is often used to obtain a better approximation of the sampling distribution of a statistic than its theoretical distribution provides. Bootstrapping is amore robust method to generate and create a sampling distribution. This generated distribution is then used to compute $p$-values, test hypothesis, and generate confidence intervals for direct and indirect effects (e.g., Erceg-Hurn \& Mirosevich, 2008). Further, we trimmed the path models to reduce the number of non-significant paths. Trimming contributed positively to the model's fit.

Additionally, to assessed whether the path model of birthing trauma effects on IQ and mental health and this of proliferation dynamics is invariant across gender (males and females), and across cultural groups (Iraqi refugee and African American adolescents), we conducted multi-group invariance analysis. Four nested models were tested sequentially: a configural invariance model, a metric invariance model, a scalar invariance model, and a strict invariance model. In the configural model, (i.e., equal form), the parameters are all freely estimated across groups. In the metric model (i.e. weak or partial invariance), the parameters are constrained to be identical across groups. In the scalar model or "strong invariance", variables and paths variances are set to be equal across groups. Lastly, the strict model "strict invariance" additionally constrains the residuals to be the same across the groups.

\section{Results}

\subsection{Descriptive and Zero-Order Correlations}

Eighty percent of Iraqis in the sample reported that they do not have a complicated birth (mean $=.28, \mathrm{SD}=.61$ ) while $76.7 \%$ of African Americans reported that they do not have it (mean $=.38, \mathrm{SD}=.73$ ), with $78.8 \%$ of the 
combined groups reported no complicated birth (mean $=.32$, $\mathrm{SD}=.67$ ). In current study birthing, trauma (BT) was correlated with PTSD, and its reexperiencing, arousal, and dissociation/numbness sub-scales, with CTD and its depression/anxiety/somatization as well as psychoticism/dissociation subscales, and with AA scale. It was negatively associated with IQ and its perceptual reasoning, working memory and processing speed sub-scales, and positively associated with discrepancy index.

In the other two previous studies (Palestinian adolescents and mental health clinic adult patients in the US) birthing trauma showed similar associations with the same and different mental health variables measured in these studies. Further, it showed apositive association with poor health and negative associations with stress-related growth and futuristic orientation in the Palestinian adolescents' sample. Table 1 includes the results of the zero order (linear) correlation between BT and the other variables in the three samples.

For trauma exposure, all the participants except one reported having endured at least four trauma types ( $\mathrm{M}=$ 9.17, $\mathrm{SD}=3.88$ for the whole sample, $\mathrm{M}=9.97, \mathrm{SD}=4.14$ for $\mathrm{AAA}$, and $\mathrm{M}=8.47$, $\mathrm{SD}=3.53$ ). The two groups had different trauma profiles, with AAAs significantly more traumatized. IRAs experienced multiple war traumas, uprootedness, acculturation challenges, political oppression in their homeland, and discrimination in their country of resettlement. AAAs had experienced more socially and family-made traumas. AAAs reported

Table 1. Zero order correlations between complicated birth, mental health variables and IQ variables in African American and Iraqi refugee Adolescents $(\mathrm{N}=410)$ compared to Palestinian adolescents $(\mathrm{N}=442)$, and mental health clinic adult clients in US ( $\mathrm{N}=399)$.

\begin{tabular}{|c|c|c|c|}
\hline Mental Health Variables & $\begin{array}{l}\text { Iraqi refugee and African } \\
\text { American Adolescents } \\
\text { (Current Study) }\end{array}$ & $\begin{array}{l}\text { Mental Health Adult } \\
\text { Clinic Clients USA } \\
(\mathrm{N}=399)\end{array}$ & $\begin{array}{l}\text { Palestinians Adolescents } \\
\qquad(\mathrm{N}=442)\end{array}$ \\
\hline Poor Health & $.09+$ & NM & $.17^{* * *}$ \\
\hline PTSD Scale & $.15^{* *}$ & $.12^{*}$ & $.23^{* * *}$ \\
\hline CTD Scale & $.16^{* * *}$ & $.08+$ & $.22^{* * *}$ \\
\hline DASS_Anxiety Scale & NM & $.17^{* * *}$ & $.25^{* * *}$ \\
\hline CTD-Depression/Anxiety/Somatization & $.23^{* * *}$ & $.10^{*}$ & $.20^{* * *}$ \\
\hline CTD-Executive Function Deficits & $.09+$ & .05 & $.11^{*}$ \\
\hline CTD-Psychoticism/Dissociation) & $.10^{*}$ & $.10^{*}$ & $.13^{* *}$ \\
\hline CTD-Suicidality & .08 & .06 & $.23^{* * *}$ \\
\hline PTSD Re-Experiencing & $.10^{*}$ & $.13^{* *}$ & $.22^{* * *}$ \\
\hline PTSD Avoidance & .05 & $.12^{*}$ & $.20^{* * *}$ \\
\hline PTSD Arousal & $.18^{* * *}$ & $.12^{*}$ & $.15^{* * *}$ \\
\hline PTSD Dissociation & $10^{*}$ & .06 & $.17^{* * *}$ \\
\hline Annihilation Anxiety Scale & $.16^{* * *}$ & NM & $.32^{* * * *}$ \\
\hline Stress Related Growth Scale & NM & NM & $-.11^{*}$ \\
\hline Futuristic Orientation Scale & NM & NM & $-.12^{*}$ \\
\hline IQ & $-.14^{* *}$ & NM & NM \\
\hline Processing Speed & $-.10^{*}$ & NM & NM \\
\hline Working Memory & $-.12^{*}$ & NM & NM \\
\hline Perceptual Reasoning & $-.17^{* * *}$ & NM & NM \\
\hline Verbal Comprehension & -.04 & NM & NM \\
\hline Discrepancy between Verbal and Perceptual & $.14^{* *}$ & NM & NM \\
\hline
\end{tabular}

Note: $+<.10$ (close to significant). ${ }^{*} p<.05 ;{ }^{* *} p<.01 ;{ }^{* * *} p<.001$; $\mathrm{NM}=$ The variable was not measured in the sample. 
having been exposed to significantly more attachment disruptions. In the AAA subsample, $7.5 \%$ were abandoned by their mother, $2.9 \%$ separated from both parents, 3.5\% were adopted, $6.4 \%$ experienced being in foster care, and $8.1 \%$ experienced frequent changes in caregivers. IRAs reported zero of such attachment disruptions. For AAA, $15.6 \%$, abandoned by their father ( $2 \%$ for IRA), and $23 \%$ their parents divorced ( $2 \%$ for IRA). Among IRAs, $11 \%$ witnessed one of their parents or a close friend being killed compared to $1 \%$ for AAAs. Among IRAs, 37\% had had one of their parents involved in combat compared to 3.5\% for AAAs. Among IRAs, $13 \%$ had had one or more parents tortured compared to 1\% for AAAs (Kira, Somers, Lewandowski, \& Chiodo, 2012).

\subsection{Path Analysis Results}

The results of the first path model confirmed the first and second hypotheses of the study concerning its effects on mental health and neurocognitive functioning. The first path model we tested had birthing trauma and cumulative traumas (other than birthing trauma) as independent variables. As explained before, the goal of introducing cumulative trauma as the independent variable was to control for other traumas cumulative effects as potential confounding factors. In this model, mental health variables (PTSD, CTD, and AA), IQ variables (verbal comprehension, perceptual reasoning, processing speed and working memory) and discrepancy index (discrepancy between perceptual reasoning and verbal comprehension) are entered as dependent and/or mediating/ moderating variables. The model fit nicely (Chi-square 21.909, d.f. $=24, p=.585, C F I=.100, R M S E A=.000$ ).

In this model cumulative trauma (other than birthing trauma) directly predicted anincrease in AA, directly and indirectly, predicted anincrease in PTSD and CTD symptoms and adecrease in processing speed. It indirectly predicted adecrease in verbal comprehension, perceptual reasoning and working memory.

Birthing trauma, in the model, directly predicted AA, directly and indirectly, predicted adecrease in perceptual reasoning and increase in the discrepancy. It indirectly predicted adecrease in verbal comprehension, processing speed and working memory and increase in PTSD and CTD. Discrepancy accounted for the highest variance I the model $(\mathrm{R}$ square $=.925)$, followed by PTSD $(\mathrm{R}$ square $=.342)$. Figure 1 presents the direct effects and Table 2 presents the direct, indirect and total effects of each variable and its 95\% confidence intervals.

The second path model confirmed the third hypothesis concerning BT proliferation dynamics. The second path model that tested the birthing trauma proliferation hypothesis fitted well (Chi Square $=9.862, d . f .=8, p$ $=.275, C F I=.995$, RMSEA $=.024)$. In this model birthing trauma has direct positive effects on attachment traumas, and direct and indirect positive effects on personal identity (mostly early childhood traumas, e.g., physical and sexual abuse and neglect) and interdependence (secondary) traumas and indirect positive effects on the other trauma types (role identity, i.e., achievement, collective identity, family and survival traumas). Attachment traumas (AT) have direct positive effects on personal identity traumas and direct and indirect positive effects on role identity and family traumas. ATs have indirect positive effects on interdependence and survival traumas. Personal identity traumas have direct positive effects on interdependence traumas and direct and indirect positive effects on collective identity traumas, and indirect positive effects on role identity and survival traumas. Interdependence traumas have direct positive effects on role identity (achievement) traumas, and direct and indirect positive effects on collective identity, family and survival traumas. Role identity traumas have direct and indirect positive effects on survival traumas. Collective identity trauma has direct negative effects on family traumas, and direct positive and indirect negative effects on survival traumas. Its total effects are positive. Family traumas have direct positive effects on survival traumas. Figure 2 presents the direct effects and Table 3 presents the direct, indirect and total effects of each variable and its $95 \%$ confidence intervals.

\subsection{Multigroup Invariance Results}

Given that the data showed reasonable fit to the two path models, a series of multigroup analyses were conducted to examine the structural invariance of the model across gender and cultural groups. For the first path model (the BT negative effects on neurocognitive functioning and mental health variables), we tested the model invariance between both gender and cultural groups. For configural invariance (same variables and paths for each variable across the three groups), results showed an acceptable model fit in both groups. Hence, our conclusion was that the variables and paths for each variable were invariant across the gender and cultural groups, configural invariance is important for the model testing as it indicates that the same variables and paths are invariant. 
Table 2. Decomposition of standardized direct, indirect, and total effects of birthing trauma and other cumulative life-time traumas on PTSD, AA, CTD, IQ variables and discrepancy in African American and Iraqi refugee adolescents.

\begin{tabular}{|c|c|c|c|c|c|c|c|c|}
\hline \multirow{2}{*}{ Causal Variables } & \multicolumn{8}{|c|}{ Endogenous Variables } \\
\hline & AA & $\begin{array}{c}\text { Verbal } \\
\text { Comprehension }\end{array}$ & $\begin{array}{l}\text { Perceptual } \\
\text { Reasoning }\end{array}$ & $\begin{array}{l}\text { Working } \\
\text { Memory }\end{array}$ & $\begin{array}{l}\text { Discrepancy } \\
\text { Index }\end{array}$ & PTSD & $\begin{array}{l}\text { Processing } \\
\text { Speed }\end{array}$ & CTD \\
\hline
\end{tabular}

Other Cumulative Life Traumas

$\begin{array}{ccccccccc}\text { Direct Effects } & .21^{* * *} & & & & & .30^{* * *} & -.10^{*} & .11^{* *} \\ & (.10 / .32) & - & - & - & - & (.19 / .40) & (-.20 /-.02) & (.02 / .21) \\ \text { Indirect Effects } & & -.02^{*} & -.01^{*} & -.01^{*} & -.01 & .02^{* *} & -.01^{*} & .17^{* * *} \\ & & (-.06 / .00) & (-.03 / .00) & (-.03 / .00) & (-.03 / .00) & (.01 / .06) & (-.02 / .00) & (.11 / .28) \\ \text { Total Effects } & .21^{* * *} & -.02^{*} & -.01^{*} & -.01^{*} & -.01 & .32^{* * *} & -.11^{*} & .28^{* * *} \\ & (.10 / .32) & (-.06 / .00) & (-.03 / .00) & (-.03 / .00) & (-.03 / .00) & (.22 / .43) & (-.21 /-.02) & (.18 / .39)\end{array}$

\section{Birthing Trauma}

\begin{tabular}{|c|c|c|c|c|c|c|c|c|}
\hline Direct Effects & $\begin{array}{c}.11^{*} \\
(.01 / .21)\end{array}$ & - & $\begin{array}{c}-.15^{* * *} \\
(-.23 /-.07)\end{array}$ & - & $\begin{array}{c}.02^{* *} \\
(.01 / .05)\end{array}$ & - & - & - \\
\hline Indirect Effects & - & $\begin{array}{c}-.01^{*} \\
(-.03 / .00)\end{array}$ & $\begin{array}{c}-.01^{*} \\
(-.02 / .00)\end{array}$ & $\begin{array}{c}-.07^{* * *} \\
(-.11 /-.03)\end{array}$ & $\begin{array}{c}.13^{* * *} \\
(.06 / .20)\end{array}$ & $\begin{array}{c}.03^{* * *} \\
(.01 / .06)\end{array}$ & $\begin{array}{c}-.05^{* * *} \\
(-.09 /-.03)\end{array}$ & $\begin{array}{c}.02^{* * *} \\
(.01 / .03)\end{array}$ \\
\hline Total Effects & $\begin{array}{c}.11^{*} \\
(.01 / .21)\end{array}$ & $\begin{array}{c}-.01^{*} \\
(-.03 / .00)\end{array}$ & $\begin{array}{c}-.16^{* * *} \\
(-.24 /-.08)\end{array}$ & $\begin{array}{c}-.07^{* * *} \\
(-.11 /-.03)\end{array}$ & $\begin{array}{c}.15^{* * *} \\
(.08 / .23)\end{array}$ & $\begin{array}{c}.03^{* * *} \\
(.01 / .06)\end{array}$ & $\begin{array}{c}-.05^{* * *} \\
(-.09 /-.03)\end{array}$ & $\begin{array}{c}.02^{* * *} \\
(.01 / .03)\end{array}$ \\
\hline Squared R & .067 & .011 & .226 & .317 & .925 & .135 & .233 & .342 \\
\hline
\end{tabular}

Note: $+<.10$ (close to significant). ${ }^{*} p<.05 ;{ }^{* *} p<.01 ;{ }^{* * *} p<.001$.

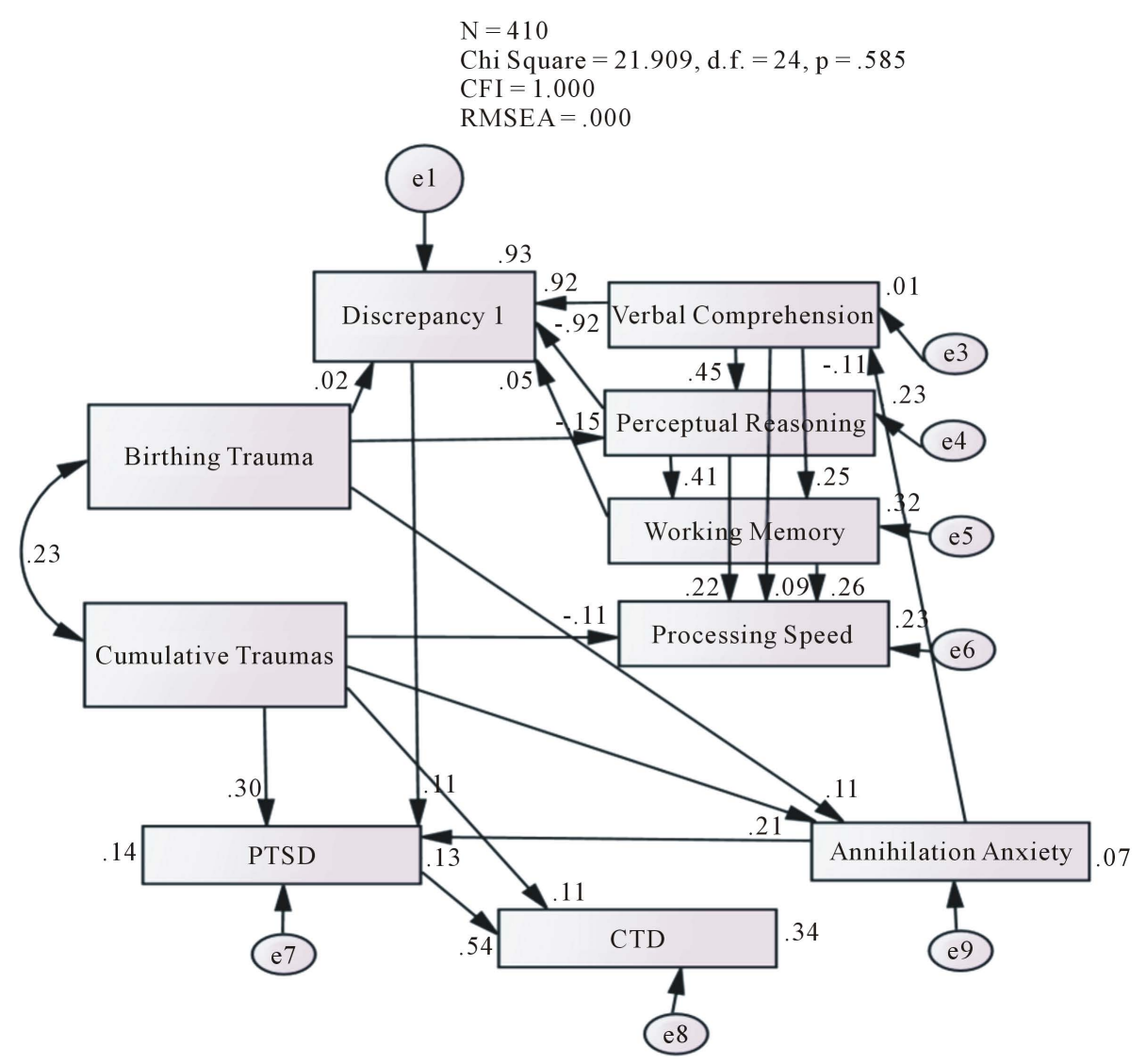

Figure 1. Path diagram for the direct effects of birthing trauma controlling for other cumulative life-time traumas on PTSD, AA, CTD, IQ variables and discrepancy in African American and Iraqi refugee adolescents. 
Table 3. Decomposition of standardized direct, indirect, and total effects of birthing trauma on other trauma types in African American and Iraqi refugee adolescents.

\begin{tabular}{|c|c|c|c|c|c|c|c|}
\hline \multirow[b]{2}{*}{ Causal Variables } & \multicolumn{7}{|c|}{ Endogenous Variables } \\
\hline & $\begin{array}{l}\text { Abandonment } \\
\text { Trauma }\end{array}$ & $\begin{array}{l}\text { Personal } \\
\text { Identity } \\
\text { Trauma }\end{array}$ & $\begin{array}{c}\text { Interdependence } \\
\text { Trauma }\end{array}$ & $\begin{array}{c}\text { Role Identity } \\
\text { (Achievement) } \\
\text { Trauma }\end{array}$ & $\begin{array}{l}\text { Collective } \\
\text { Identity } \\
\text { Trauma }\end{array}$ & $\begin{array}{l}\text { Family } \\
\text { Trauma }\end{array}$ & $\begin{array}{l}\text { Survival } \\
\text { Trauma }\end{array}$ \\
\hline \multicolumn{8}{|l|}{ Birthing Trauma } \\
\hline Direct Effects & $\begin{array}{c}.15^{*} \\
(.04 / .27)\end{array}$ & $\begin{array}{c}.19^{* *} \\
(.10 / .29)\end{array}$ & $\begin{array}{c}.09^{*} \\
(.03 / .18)\end{array}$ & - & - & $\longrightarrow$ & - \\
\hline Indirect Effects & $\longrightarrow$ & $\begin{array}{c}.03^{*} \\
(.01 / .06)\end{array}$ & $\begin{array}{c}.09^{* *} \\
(.05 / .15)\end{array}$ & $\begin{array}{c}.07^{* * *} \\
(.04 / .11)\end{array}$ & $\begin{array}{c}.09^{* * *} \\
(.06 / .15)\end{array}$ & $\begin{array}{l}.08^{* * *} \\
(.04 / .14)\end{array}$ & $\begin{array}{c}.09^{* * *} \\
(.05 / .15)\end{array}$ \\
\hline Total Effects & $\begin{array}{c}.15^{*} \\
(.04 / .27)\end{array}$ & $\begin{array}{c}.22^{* *} \\
(.13 / .33)\end{array}$ & $\begin{array}{c}.18^{* *} \\
(.10 / .28)\end{array}$ & $\begin{array}{c}.07^{* * *} \\
(.04 / .11)\end{array}$ & $\begin{array}{c}.09^{* * *} \\
(.06 / .15)\end{array}$ & $\begin{array}{l}.08^{* * *} \\
(.04 / .14)\end{array}$ & $\begin{array}{c}.09^{* * *} \\
(.05 / .15)\end{array}$ \\
\hline
\end{tabular}

\section{Attachment Trauma}

\begin{tabular}{|c|c|c|c|c|c|c|c|}
\hline Direct Effects & - & $\begin{array}{c}.20^{*} \\
(.09 / .29)\end{array}$ & $\begin{array}{c}.07 \\
(-.01 / .17)\end{array}$ & $\begin{array}{c}.13^{*} \\
(.02 / .24)\end{array}$ & $\longrightarrow$ & $\begin{array}{c}.20^{* *} \\
(.11 / .32)\end{array}$ & - \\
\hline Indirect Effects & $\longrightarrow$ & - & $\begin{array}{c}.07^{* *} \\
(.04 / .11)\end{array}$ & $\begin{array}{c}.05^{* *} \\
(.02 / .09)\end{array}$ & $\begin{array}{c}.09^{* *} \\
(.06 / .17)\end{array}$ & $\begin{array}{c}.04^{*} \\
(.01 / .08)\end{array}$ & $\begin{array}{c}.13^{* *} \\
(.08 / .19)\end{array}$ \\
\hline Total Effects & $\longrightarrow$ & $\begin{array}{c}.20^{*} \\
(.09 / .29)\end{array}$ & $\begin{array}{c}.14^{* *} \\
(.05 / .23)\end{array}$ & $\begin{array}{c}.18^{* *} \\
(.08 / .32)\end{array}$ & $\begin{array}{c}.09^{* *} \\
(.06 / .17)\end{array}$ & $\begin{array}{c}.24^{* *} \\
(.14 / .33)\end{array}$ & $\begin{array}{c}.13^{* *} \\
(.08 / .19)\end{array}$ \\
\hline \multicolumn{8}{|c|}{ Personal Identity Trauma } \\
\hline Direct Effects & - & - & $\begin{array}{c}.35^{* *} \\
(.26 / .47)\end{array}$ & $\begin{array}{c}.12 \\
(-.00 / .23)\end{array}$ & $\begin{array}{c}.15^{*} \\
(.04 / .28)\end{array}$ & $\begin{array}{c}.13 \\
(-.03 / .30)\end{array}$ & $\longrightarrow$ \\
\hline Indirect Effects & $\longrightarrow$ & $\longrightarrow$ & - & $\begin{array}{c}.05^{* *} \\
(.02 / .09)\end{array}$ & $\begin{array}{c}.12^{* *} \\
(.08 / .20)\end{array}$ & $\begin{array}{c}.02 \\
(-.02 / .07)\end{array}$ & $\begin{array}{c}.20^{* *} \\
(.14 / .28)\end{array}$ \\
\hline Total Effects & $\longrightarrow$ & 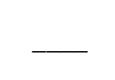 & $\begin{array}{c}.35^{* *} \\
(.26 / .47)\end{array}$ & $\begin{array}{c}.17^{* *} \\
(.06 / .29)\end{array}$ & $\begin{array}{c}.27^{* *} \\
(.14 / .37)\end{array}$ & $\begin{array}{c}.15^{*} \\
(.03 / .29)\end{array}$ & $\begin{array}{c}.20^{* *} \\
(.14 / .28)\end{array}$ \\
\hline \multicolumn{8}{|c|}{ Interdependence Trauma } \\
\hline Direct Effects & & & - & $\begin{array}{c}.15^{*} \\
(.04 / .25)\end{array}$ & $\begin{array}{c}.31^{* *} \\
(.19 / .41)\end{array}$ & $\begin{array}{c}.16^{*} \\
(.05 / .24)\end{array}$ & $\begin{array}{c}.30^{*} \\
(.18 / .38)\end{array}$ \\
\hline Indirect Effects & & & - & - & $\begin{array}{c}.02^{*} \\
(.00 / .05)\end{array}$ & $\begin{array}{c}-.04^{* *} \\
(-.08 /-.01)\end{array}$ & $\begin{array}{c}.10^{* *} \\
(.06 / .16)\end{array}$ \\
\hline Total Effects & & & $\longrightarrow$ & $\begin{array}{c}.15^{*} \\
(.04 / .25)\end{array}$ & $\begin{array}{c}.33^{* *} \\
(.20 / .44)\end{array}$ & $\begin{array}{c}.12^{*} \\
(.01 / .21)\end{array}$ & $\begin{array}{c}.40^{* *} \\
(.27 / .47)\end{array}$ \\
\hline \multicolumn{8}{|c|}{ (Role Identity) Achievement Trauma } \\
\hline Direct Effects & & & & - & $\begin{array}{c}.11 \\
(-.01 / .21)\end{array}$ & - & $\begin{array}{c}.11^{*} \\
(.07 / .31)\end{array}$ \\
\hline Indirect Effects & & & - & $\longrightarrow$ & - & $\begin{array}{c}-.01+ \\
(-.04 /-.00)\end{array}$ & $\begin{array}{c}.01^{*} \\
(.00 / .07)\end{array}$ \\
\hline Total Effects & & 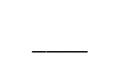 & $\square$ & 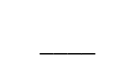 & $\begin{array}{c}.11 \\
(-.01 / .21)\end{array}$ & $\begin{array}{c}-.01+ \\
(-.04 /-.00)\end{array}$ & $\begin{array}{c}.12^{*} \\
(.02 / .22)\end{array}$ \\
\hline \multicolumn{8}{|c|}{ Collective Identity Trauma } \\
\hline Direct Effects & & & & - & - & $\begin{array}{c}-.11^{*} \\
(-.21 /-.03)\end{array}$ & $\begin{array}{c}.17^{*} \\
(.07 / .31)\end{array}$ \\
\hline Indirect Effects & & & & & 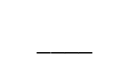 & - & $\begin{array}{c}-.02^{*} \\
(-.05 /-.01)\end{array}$ \\
\hline Total Effects & & 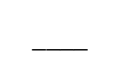 & 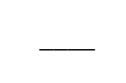 & 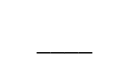 & $\overline{ }$ & $\begin{array}{c}-.11^{*} \\
(-.21 /-.03)\end{array}$ & $\begin{array}{c}.15^{*} \\
(.06 / .30)\end{array}$ \\
\hline \multicolumn{8}{|l|}{ Family Trauma } \\
\hline Direct Effects & & 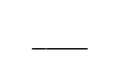 & - & - & 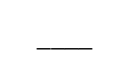 & $\longrightarrow$ & $\begin{array}{c}.22^{*} \\
(.10 / .29)\end{array}$ \\
\hline Indirect Effects & 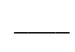 & - & - & $\longrightarrow$ & $\longrightarrow$ & - & - \\
\hline Total Effects & & $\bar{z}$ & - & $\longrightarrow$ & $\longrightarrow$ & - & $\begin{array}{c}.22^{*} \\
(.10 / .29)\end{array}$ \\
\hline Squared R & .021 & .086 & .161 & .081 & .186 & .105 & .266 \\
\hline
\end{tabular}




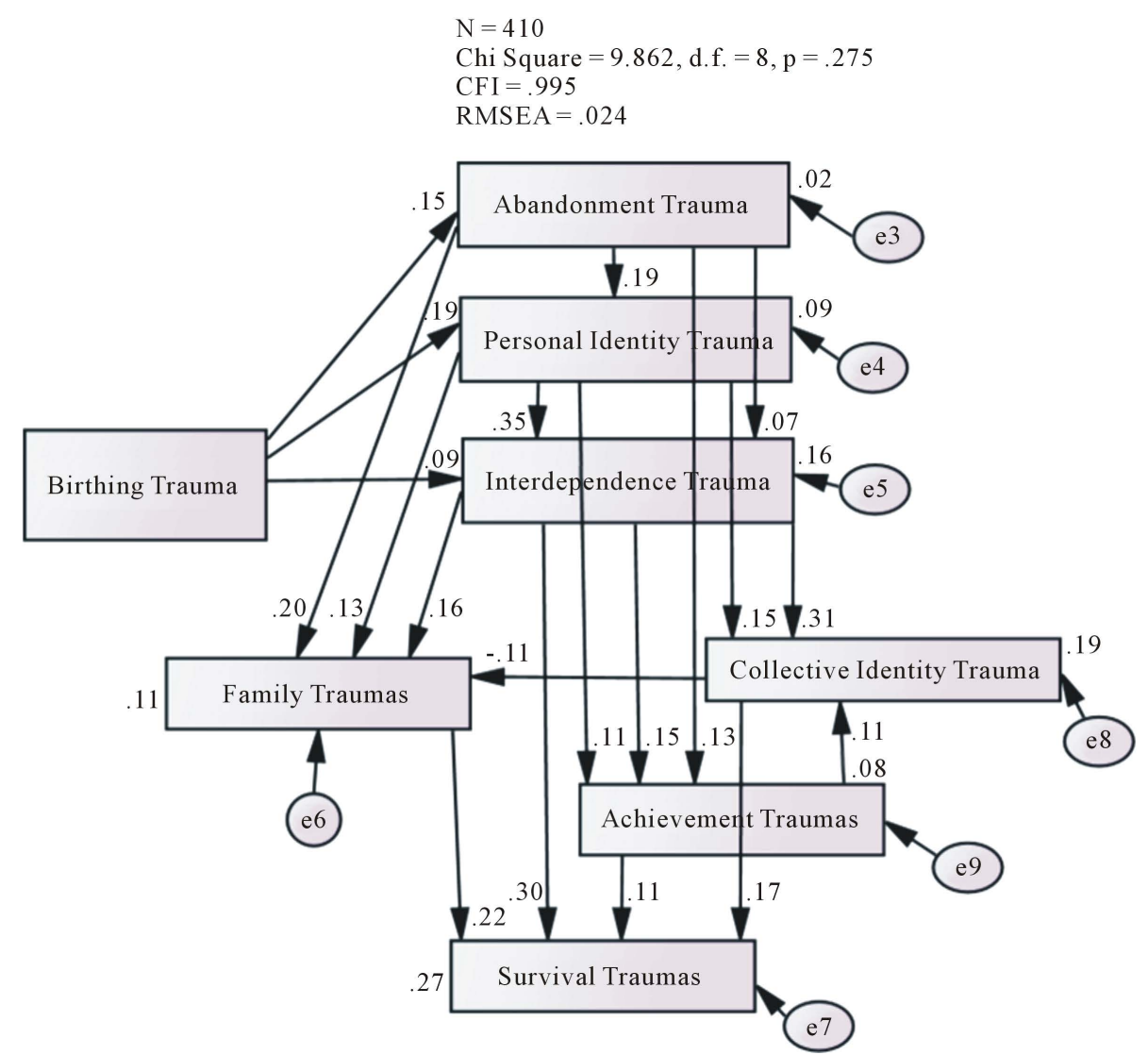

Figure 2. Path diagram that depicts the direct proliferation of birthing trauma to other life trauma types.

The second model (metric or weak invariance) model (holding all variables and paths values invariant across groups) fits as well for both gender and cultural groups. Specifying the variable and paths' variances to be invariant in the second model did not result in a significant decrease in RMSEA (less than .015 for RMSEA), or a significant decrease in CFI and IFI which means that the model is invariant at this level of analysis across genders and cultures.

In the third model (strong invariance or scalar invariance model in which intercepts are additionally restrained), the fit indices are acceptable as well which indicate the model is strongly invariant across gender and cultural groups. The fourth model (strict invariance model in which residuals additionally restrained), the fit indicators, are out of the accepted range. Table 4 details the fit indices for each model across gender and cultural groups.

For the second path model (BT proliferation), we followed the same sequence of analysis. For configural invariance, results showed an acceptable model fit in both groups. The second model (metric or weak invariance) fits as well for both gender, but not for cultural groups. Specifying the variable and paths' variances to be invariant in the second model did not result in a significant decrease in RMSEA (less than .015 for RMSEA), or significant decrease in CFI and IFI in gender groups, which means that the model is invariant at this level of analysis across gender, but not across culture.

In the third model (strong invariance or scalar invariance model in which intercepts are additionally restrained), the fit indices are acceptable for gender groups and not for cultural groups which indicate the model is strongly invariant across gender but not across cultural groups. The fourth model (strict invariance model in which residuals additionally restrained), the fit indicators, are out of the accepted range for both groups. Table 5 details the fit indices for each model across gender and cultural groups.

The results supported research hypothesis that the BT effects and proliferation models are at least invariant in the form across gender and cultural groups. However, the results confirmed strong invariance of the two models 
Table 4. Multigroup invariance analysis of the path model of the effects of birthing trauma on IQ and on mental health variables between cultural and gender groups.

\begin{tabular}{|c|c|c|c|c|c|c|c|}
\hline \multicolumn{8}{|c|}{ Fit Indices for Multi-Group Invariance between Cultural Groups (IRA and AAA) } \\
\hline & $x^{2}$ & $d f$ & $p$ & $x^{2} / d f$ & CFI & RMSEA & IFI \\
\hline Configural (Structure) & 37.524 & 46 & .809 & .816 & 1.000 & .000 & 1.000 \\
\hline Metric (Weights) & 106.572 & 67 & .002 & 1.591 & .970 & .042 & .971 \\
\hline Scalar (Intercepts) & 129.724 & 75 & .000 & 1.730 & .959 & .047 & .960 \\
\hline Strict Invariance & 168.117 & 88 & .000 & 1.910 & .940 & .052 & .940 \\
\hline \multicolumn{8}{|c|}{ Fit Indices for Multi-Group Invariance between Gender Groups (Males and Females) } \\
\hline & $x^{2}$ & $d f$ & $p$ & $x^{2} / d f$ & CFI & RMSEA & IFI \\
\hline Configural (Structure) & 27.050 & 46 & .988 & .588 & 1.000 & .000 & 1.012 \\
\hline Metric (Weights) & 109.540 & 67 & .001 & 1.635 & .972 & .042 & .972 \\
\hline Scalar (Intercepts) & 165.414 & 75 & .000 & 2.206 & .940 & .058 & .941 \\
\hline Strict Invariance & 266.956 & 88 & .000 & 3.034 & .881 & .075 & .881 \\
\hline
\end{tabular}

Table 5. Multigroup invariance analysis of the path model of birthing trauma proliferation between cultural groups and gender (males and females).

\begin{tabular}{|c|c|c|c|c|c|c|c|}
\hline \multicolumn{8}{|c|}{ Fit Indices for Multi-Group Invariance between Gender Groups (Males and Females) } \\
\hline & $x^{2}$ & $d f$ & $p$ & $x^{2} / d f$ & CFI & RMSEA & IFI \\
\hline Configural (Structure) & 19.262 & 16 & .255 & 1.204 & .991 & .024 & .992 \\
\hline Metric (Weights), & 52.537 & 36 & .037 & 1.459 & .953 & .036 & .956 \\
\hline Scalar (Intercepts) & 57.762 & 43 & .066 & 1.343 & .958 & .031 & .960 \\
\hline Strict Invariance & 134.700 & 52 & .000 & 2.590 & .767 & .066 & .769 \\
\hline \multicolumn{8}{|c|}{ Fit Indices for Multi-Group Invariance between Cultural Groups (IRA and AAA) } \\
\hline & $x^{2}$ & $d f$ & $p$ & $x^{2} / d f$ & CFI & RMSEA & IFI \\
\hline Configural (Structure) & 14.281 & 14 & .429 & 1.020 & .999 & .008 & .999 \\
\hline Metric (Weights), & 96.723 & 35 & .000 & 2.764 & .827 & .073 & .837 \\
\hline Scalar (Intercepts) & 179.456 & 42 & .000 & 4.273 & .615 & .099 & .630 \\
\hline Strict Invariance & 551.998 & 51 & .000 & 10.823 & .000 & .171 & -.382 \\
\hline
\end{tabular}

across gender groups and strong invariance of the BT negative effects on neurocognitive functioning and mental health across gender groups only. Lack of strong invariance in trauma proliferation across cultural group may be a result of different trauma profiles for each cultural group with presence or absence of some trauma types in each trauma profile.

\section{Discussion}

The current study is significant, being the first study that provided empirical evidence of the emotional and neurocognitive impact of birthing trauma, controlling for other life traumas. Further, the current study is the first to illustrate trauma proliferation dynamics based on theory and empirical evidence using path analysis path analysis. Birthing trauma (BT), the first trauma in life may cause a restricted mood for the infant. In addition, PTSD and depression following difficult birth put mothers at high risk of impairment in their relationships with their infants, which foster insecure attachment style in the baby (Bailham \& Joseph, 2003; Ross \& McLean, 2006; 
Parfitt \& Ayers, 2009; Forcada-Guex, Borghini, Pierrehumbert, Ansermet, \& Muller-Nix, 2011). Such factors interfere with the quality of child attachment which has enduring effects on interpersonal relationships. Such attachment disruptions proliferate and initiate a cascade of increased vulnerability to personal identity traumas (e.g., sexual and physical abuse), interdependence and other interpersonal traumas. BTs direct effects on these three trauma types trickle down and proliferate indirectly to other trauma types (role Identity (achievement), collective identity, and family and survival traumas. It is worth noting that exception to these proliferation sequelae is the direct negative effects (restricting the proliferation processes) of collective identity traumas (e.g., discriminations) on family traumas. Such trauma types may (e.g., discriminations) distract from the focus on the family and decrease vulnerability to family traumas (e.g., increase focus on family protection). The proliferation dynamics may not be so automatic for some trauma types. However, such proliferation dynamics of early life traumas may explain in part its profound effects on mental health and neurocognitive functioning.

Another factor that may contribute to IQ results is the potential direct medical complications of difficult birth and its severity (which was not measured in current research). Difficulties related to the birth's physical context (e.g., the umbilical cord is looped around the baby's neck possibly causing compression, jaundice, or prolonged pregnancy) or medical procedures utilized, all are potentially injurious to the infant central nervous system.

On another vein, BT's direct effects on existential anxiety (AA) and CTD trickle down to increased PTSD symptoms. BT is associated directly with (AA) that may alter threat perceptions and increases vulnerability to PTSD. BT indirect effects on PTSD may be reflected also in the nature of the potential implicit memory in BT experience. Further, BT negative effects on cognitive functioning and IQ are significant and may have a trickling down effect to other areas of functioning increasing vulnerability and intensifying trauma proliferation dynamics. BT positive effects on discrepancy may have negative neurological ramifications. Significant discrepancies between major IQ indexes found to be sensitive markers for pathologies (Binder, 1976; Bornstein \& Matarazzo, 1982). Similarly, previous studies found negative linear and nonlinear effects of severe trauma on increased IQ discrepancy index (e.g., perceptual reasoning vs. verbal comprehension) (e.g., Kira, Lewandowski, Somers, Yoon, \& Chiodo, 2012).

Previous studies of the relationship between traumatic stress and IQ provide support for the association between some trauma types (e.g., exposure to violence and assault), PTSD, and significant decrements in IQ or one of its components (e.g., Bremner, Vermetten, Afzal, \& Vythilingam, 2004; Delaney-Black et al., 2002; Kira, Lewandowski, Somers, Yoon, \& Chiodo, 2012). Breslau, Lucia, and Alvarado (2006), in a longitudinal study of the relationship between IQ and trauma exposure, found that higher IQ had a significant role in avoiding exposure to traumatic events, especially to assault types of trauma and thus to subsequent PTSD.

Further, the results emphasized the importance for early proactive interventions with victims of BT, to minimize its proliferation and mental health dynamics and provide special help for the child and parents. Supporting traumatized mother after difficult birth to help to establish healthy attachment with the baby can help diffuse the vicious cycle of trauma proliferation initiated by birthing trauma. Mothers' parent training should attenuate much of the effect of a negative birth. For example, training on Kangaroo Care, which demonstrates that mothers holding their babies skin-to-skin after a difficult birth can downregulate the stress responses for both mother and baby (Ludington-Hoe, Morgan, \& Abouelfettoh, 2008; Nyqvist et al., 2010; Phillips, 2013). Supporting traumatized developing infants with extra emotional and educational help, and enrichment activities should help minimize the effects of birthing trauma.

The current study has several limitations. One of the limitations is that the measures we used were based on participants' self-reports, which could be subject to under- or over-reporting of events due to current symptoms, embarrassment, shame, or social desirability. The study did not use an independent measure of the birth's difficulty that quantifies a difficult birth. For example, was the baby preterm? Did he/she spend time in the neonatal intensive care? Did they have any life-threatening complications? Did they have many procedures (needle sticks, intubation, and surgery)? Did they sustain an injury as the result of a birth (e.g., injury to the scalp or head, broken collar bone or arm?). Or was it simply a matter of a long labor? Also, there are many potential pre-or post-natal additional intervening events that may have happened to the mother or the infant that confounded the results, other than the cumulative life traumas we controlled for in the study. Such potential confounding factors that may facilitate blocking or activating spreading of trauma proliferation were not included in the conceptual model or in the empirical study. In addition, the study used a cross-sectional design and, as a result, only probabilistic relationships can be drawn from the results. Future studies are needed to replicate these results through more sophisticated longitudinal and/experimental designs, using medical records to determine the severity of BT 
and include other potential confounding variables. Future studies may focus on identifying such natural or intervention factors to help develop interventions that block such proliferation. Intervention models that include inoculation against trauma proliferation and stress generation are emerging (e.g., Kira, Lewandowski, Ashby, \& Omidy, 2015).

Otherwise, the results provided initial evidence of the validity of birthing trauma framework, of its proliferation dynamics, and the potential validity and utility DBTF framework in trauma work.

\section{References}

Arbuckle, J. L. (2006). Amos 7.0 User's Guide. Chicago: SPSS.

Bailham, D., \& Joseph, S. (2003). Post-Traumatic Stress Following Childbirth: A Review of the Emerging Literature and Directions for Research and Practice. Psychology, Health \& Medicine, 8, 159-168. http://dx.doi.org/10.1080/1354850031000087537

Beck, C. T. (2010). Subsequent Childbirth after a Previous Traumatic Birth. Nursing Research, 59, 241-249. http://dx.doi.org/10.1097/NNR.0b013e3181e501fd

Beck, C. T., Gable, R. K., Sakala, C., \& Declercq, E. R. (2011). Posttraumatic Stress Disorder in New Mothers: Results from a Two-Stage US National Survey. Birth, 38, 216-227. http://dx.doi.org/10.1111/j.1523-536X.2011.00475.x

Binder, L. (1976). Hemispheric Specialization. Journal of Pediatric Psychology, 1, 34-38. http://dx.doi.org/10.1093/jpepsy/1.3.34

Blake, D. D., Weathers, F. W., Nagy, L. M., Kaloupek, D. G., Klauminzer, G., Charney, D. S., \& Keane, T. M. (1990). A Clinician Rating Scale for Assessing Current and Lifetime PTSD: The CAPS-1. The Behavior Therapist, 13, 187-188.

Bornstein, R., \& Matarazzo, J. (1982). Wechsler VIQ versus PIQ Differences in Cerebral Dysfunction: A Literature Review with Emphasis on Sex Differences. Journal of Clinical Neuropsychology, 4, 319-334. http://dx.doi.org/10.1080/01688638208401140

Bowlby, J. (1988). A Secure Base: Parent Child Attachment and Healthy Human Development. New Work: Basic Books.

Bremner, J. D., Vermetten, E., Afzal, N., \& Vythilingam, M. (2004). Deficits in Verbal Declarative Memory Functions in Women with Childhood Sexual Abuse-Related Posttraumatic Stress Disorder. Journal of Nervous and Mental Disease, 192, 643-649. http://dx.doi.org/10.1097/01.nmd.0000142027.52893.c8

Breslau, N., Lucia, V., \& Alvarado, G. (2006). Intelligence and Other Predisposing Factors in Exposure to Trauma and Posttraumatic Stress Disorder. Archives of General Psychiatry, 63, 1238-1245. http://dx.doi.org/10.1001/archpsyc.63.11.1238

Callahan, J. L., \& Hynan, M. T. (2002). Identifying Mothers at Risk for Postnatal Emotional Distress: Further Evidence for the Validity of the Perinatal Posttraumatic Stress Disorder Questionnaire. Journal of Perinatology, 22, 448-454. http://dx.doi.org/10.1038/sj.jp.7210783

Creedy, D. K., Shochet, I. M., \& Horsfall, J. (2000). Childbirth and the Development of Acute Trauma Symptoms: Incidence and Contributing Factors. Birth, 27, 104-111. http://dx.doi.org/10.1046/j.1523-536x.2000.00104.x

Daniels, J. K., Lamke, J. P., Gaebler, M., Walter, H., \& Scheel, M. (2013). White Matter Integrity and Its Relationship to PTSD and Childhood Trauma-A Systematic Review and Meta-Analysis. Depression \& Anxiety, 30, 207-216. http://dx.doi.org/10.1002/da.22044

De Bellis, M. D., \& Zisk, A. (2014). The Biological Effects of Childhood Trauma. Child and Adolescent Psychiatric Clinic ofNorth America, 23, 185-222. http://dx.doi.org/10.1016/j.chc.2014.01.002

De Schepper, S., Vercauteren, T., Tersago, J., Jacquemyn, Y., Raes, F., \& Franck, E. (2016). Post-Traumatic Stress Disorder after Childbirth and the Influence of Maternity Team Care During Labour and Birth: A Cohort Study. Midwifery, 32, 87-92. http://dx.doi.org/10.1016/j.midw.2015.08.010

Delaney-Black, V., Covington, C., Ondersma, S., Nordstrom-Klee, B., Templin, T., Ager, G. et al. (2002). Violence Exposure, Trauma, and IQ and/or Reading Deficits among Urban Children. Archives of Pediatrics and Adolescent Medicine, 156, 280-285. http://dx.doi.org/10.1001/archpedi.156.3.280

Edworth, Z. Chasey, R., \& Williams, H. (2008). The Role of Schema and Appraisals in the Development of Post-Traumatic Stress Symptoms Following Birth. Journal of Reproductive and Infant Psychology, 26, 123-138. http://dx.doi.org/10.1080/02646830801918422

Erceg-Hurn, D., \& Mirosevich, V. (2008). Modern Robust Statistical Methods: An Easy Way to Maximize the Accuracy and Power of Your Research. American Psychologist, 63, 591-601. http://dx.doi.org/10.1037/0003-066X.63.7.591

Forcada-Guex, M., Borghini, A., Pierrehumbert, B., Ansermet, F., \& Muller-Nix, C. (2011). Prematurity, Maternal Post traumatic Stress and Consequences on the Mother-Infant Relationship. Early Human Development, 87, 21-26. http://dx.doi.org/10.1016/j.earlhumdev.2010.09.006 
Ford, E., Ayers, S., \& Bradley, R. (2010). Exploration of a Cognitive Model to Predict Post-Traumatic Stress Symptoms Following Childbirth. Journal of Anxiety Disorders, 24, 353-359. http://dx.doi.org/10.1016/j.janxdis.2010.01.008

Gaensbauer, T. (2002). Representations of Trauma in Infancy: Clinical and Theoretic Implications for the Understanding of Early Memory. Infant Mental Health Journal, 23, 259-277. http://dx.doi.org/10.1002/imhj.10020

Grekin, R., \& O’Hara, M. W. (2014). Prevalence and Risk Factors of Postpartum Posttraumatic Stress Disorder: A Meta-Analysis. Clinical Psychology Review, 34, 389-401. http://dx.doi.org/10.1016/j.cpr.2014.05.003

Halperin, O., Sarid, O., \& Cwikel, J. (2015). The Influence of Childbirth Experiences on Women's Postpartum Traumatic Stress Symptoms: A Comparison between Israeli Jewish and Arab Women. Midwifery, 31, 625-632. http://dx.doi.org/10.1016/j.midw.2015.02.011

Iles, J., Slade, P., \& Spiby, H. (2011). Posttraumatic Stress Symptoms and Postpartum Depression in Couples after Childbirth: The Role of Partner Support and Attachment. Journal of Anxiety Disorders, 25, 520-530. http://dx.doi.org/10.1016/j.janxdis.2010.12.006

Kalton, G., \& Anderson, D. (1986). Sampling Rare Populations. Journal of the Royal Statistical Society, 149, 65-82. http://dx.doi.org/10.2307/2981886

Kira, I. (2001). Taxonomy of Trauma and Trauma Assessment. Traumatology, 2, 1-14. http://dx.doi.org/10.1177/153476560100700202

Kira, I. (2004). Secondary Trauma in Treating Refugee Survivors of Torture and Their Families. Torture, 14, 38-44.

Kira, I. (2010). Etiology and Treatments of Post-Cumulative Traumatic Stress Disorders in Different Cultures. Traumatology: An International Journal, 16, 128-141. http://dx.doi.org/10.1177/1534765610365914

Kira, I. A., Lewandowski, L., Ashby, J. S., \& Omidy, A. Z. (2015). Development and Piloting the MMMM Ecological Interactive Open Systems Model: A Prospective One-Year Treatment Outcome of Children of Tortured Refugees. Psychology, 6, 1277-1296. http://dx.doi.org/10.4236/psych.2015.610125

Kira, I. A., Omidy, A. Z., \& Ashby, J. S. (2014). Cumulative Trauma, Appraisal and Coping in Palestinian and American Indian Adults: Two Cross-Cultural Studies. Traumatology: An International Journal, 20, 119-133. http://dx.doi.org/10.1037/h0099397

Kira, I. A., Omidy, A. Z., Fawzi, M., Rice, K. G., Fawzi, M., Lewandowski, L., \& Bujold-Bugeaud, M. (2015). Are the Negative Mental Health Effects of Gender Discrimination (GD) Salient across Cultures? Does Self-Esteem Mediate These Effects: GD as a Continuous Traumatic Stress and the Pathways to Its Negative Dynamics? Psychology, 6, 93-116. http://dx.doi.org/10.4236/psych.2015.61009

Kira, I., Alawneh, A., Aboumediene, S., Lewandowski, L., \& Laddis, A. (2014). Dynamics of Oppression and Coping from Traumatology Perspective: The Example of Palestinian Youth. Peace and Conflict: Journal of Peace Psychology, 20, 385-411. http://dx.doi.org/10.1037/pac0000053

Kira, I., Ashby, J. S., Lewandowski, L., Alawneh, A.N., Mohanesh, J., \& Odenat, L. (2013). Advances in Continuous Traumatic Stress Theory: Traumatogenic Dynamics and Consequences of Intergroup Conflict: The Palestinian Adolescents Case. Psychology, 4, 396-409. http://dx.doi.org/10.4236/psych.2013.44057

Kira, I., Fawzi, M., \& Fawzi, M. (2013). The Dynamics of Cumulative Trauma and Trauma Types in Adults Patients with Psychiatric Disorders: Two Cross-Cultural Studies. Traumatology: An International Journal, 19, 179-195. http://dx.doi.org/10.4236/psych.2013.44057

Kira, I., Hammad, A., Lewandowski, L., Templin, T., Ramswamy, V., Ozkan, B., \& Mohanesh, J. (2007). The Health and Mental Status of Iraqi Refugees and Their Etiology. Ethnicity \& Disease, 17, 79-82.

Kira, I., Lewandowski, L., Chiodo, L., \& Ibrahim, A. (2014). Advances in Systemic Trauma Theory: Traumatogenic Dynamics and Consequences of Backlash as a Multi-Systemic Trauma on Iraqi Refugee Muslim Adolescents. Psychology, 5 , 389-412. http://dx.doi.org/10.4236/psych.2014.55050

Kira, I., Lewandowski, L., Somers, C., Yoon, J., \& Chiodo, L. (2012) PTSD, Trauma Types, Cumulative Trauma, and IQ: The Case of African American and Iraqi Refugee Adolescents. Psychological Trauma: Theory, Research, Practice, and Policy, 4, 128-139. http://dx.doi.org/10.1037/a0022121

Kira, I., Lewandowski, L., Templin, T., Ramaswamy, V., Ozkan, B., \& Mohanesh, J. (2008). Measuring Cumulative Trauma Dose, Types and Profiles Using a Development-Based Taxonomy of Trauma. Traumatology: International Journal, 14, 62-87.http://dx.doi.org/10.1177/1534765608319324

Kira, I., Somers, C., Lewandowski, L., \& Chiodo, L. (2012). Attachment Disruptions, IQ and PTSD in African American Adolescents (AAA): A Traumatology Perspective. Journal of Aggression, Maltreatment, and Trauma, 21, 665-690. http://dx.doi.org/10.1080/10926771.2012.698377

Kira, I., Templin, T., Lewandowski, L., Ashby, J. S., Oladele, A., \& Odenat, L. (2012). Cumulative Trauma Disorder Scale: Two Studies. Psychology, 3, 643-656. http://dx.doi.org/10.4236/psych.2012.39099 
Kira, I., Templin, T., Lewandowski, L., Clifford, D., Wiencek, E., Hammad, A., Al-Haidar, A., \& Mohanesh, J. (2006). The Effects of Torture: Two Community Studies. Peace and Conflict: Journal of Peace Psychology, 12, 205-228. http://dx.doi.org/10.1207/s15327949pac1203_1

Kira, I., Templin, T., Lewandowski, L., Ramaswamy, V., Bulent, O., Abu-Mediane, S., Mohanesh, J., \& Alamia, H. (2011). Cumulative Tertiary Appraisal of Traumatic Events across Cultures: Two Studies. Journal of Loss and Trauma: International Perspectives on Stress \& Coping, 16, 43-66. http://dx.doi.org/10.1080/15325024.2010.519288

Kira, I., Templin, T., Lewandowski, L., Ramaswamy, V., Bulent, O., Mohanesh, J., \& Abdulkhaleq, H. (2012). Collective and Personal Annihilation Anxiety: Measuring Annihilation Anxiety AA. Psychology, 3, 90-99. http://dx.doi.org/10.4236/psych.2012.31015

Kuhlman, K. R., Vargas, I., Geiss, E., \& Lopez-Duran, N. (2015). Age of Trauma Onset and HPA Axis Dysregulation among Trauma-Exposed Youth. Journal of Traumatic Stress, 28, 572-579. http://dx.doi.org/10.1002/jts.22054

Labonte, B., Suderman, M., Maussion, G., Navaro, L., Yerko, V., \& Mahar, I. (2012) Genome-Wide Epigenetic Regulation by Early-Life Trauma. Archives of General Psychiatry, 69, 722-731. http://dx.doi.org/10.1001/archgenpsychiatry.2011.2287

Li, S., Callaghan, B. L., \& Richardson, R. (2014). Infantile Amnesia: Forgotten but Not Gone. Learning \& Memory, 21, 135-139. http://dx.doi.org/10.1101/lm.031096.113

Liu, R. T. (2013). Stress Generation: Future Directions and Clinical Implications. Clinical Psychology Review, 33, 406-416. http://dx.doi.org/10.1016/j.cpr.2013.01.005

Ludington-Hoe, S. M., Morgan, K., \& Abouelfettoh, A. (2008). A Clinical Guideline for Implementation of Kangaroo Care with Premature Infants of 30 or More Weeks’ Postmenstrual Age. Advances in Neonatal Care, 8, S3-S23. http://dx.doi.org/10.1097/01.ANC.0000324330.25734.b6

Lupien, S. J., McEwen, B. S., Gunnar, M. R., \& Heim, C. (2009). Effects of Stress throughout the Lifespan on the Brain, Behaviour and Cognition. Nature Reviews Neurosciences, 10, 434-445. http://dx.doi.org/10.1038/nrn2639

McGowan, P. O. (2013). Epigenomic Mechanisms of Early Adversity and HPA Dysfunction: Considerations for PTSD Research. Frontiers in Psychiatry, 4, 110. http://dx.doi.org/10.3389/fpsyt.2013.00110

Misund, A. R., Nerdrum, P., Bråten, S., Pripp, A. H., \& Diseth, T. H. (2013). Long-Term Risk of Mental Health Problems in Women Experiencing Preterm Birth: A Longitudinal Study of 29 Mothers. Annals of General Psychiatry, 12, 33. http://dx.doi.org/10.1186/1744-859X-12-33

National Scientific Council on the Developing Child (2005/2014). Excessive Stress Disrupts the Architecture of the Developing Brain. Working Paper 3. Updated Edition. www.developingchild.harvard.edu

Nyqvist, K. H., Anderson, G. C., Bergman, N., Cattaneo, A., Charpak, N., Davanzo, R., et al. (2010). Towards Universal Kangaroo Mother Care: Recommendations and Report from the First European Conference and Seventh International Workshop on Kangaroo Mother Care. Acta Paediatrica, 99, 820-826. http://dx.doi.org/10.1111/j.1651-2227.2010.01787.x

Ogle, C. M., Rubin, D. C., Berntsen, D., \& Siegler, I. C. (2013). The Frequency and Impact of Exposure to Potentially Traumatic Events over the Life Course. Clinical Psychological Science, 1, 426-434. http://dx.doi.org/10.1177/2167702613485076

Ogle, C. M., Rubin, D., \& Siegler, I. C. (2013). The Impact of the Developmental Timing of Trauma Exposure on PTSD Symptoms and Psychosocial Functioning among Older Adults. Developmental Psychology, 49, 2191-2200. http://dx.doi.org/10.1037/a0031985

Onoye, J. M., Goebert, D., Morland, L., Matsu, C., \& Wright, T. (2009). PTSD and Postpartum Mental Health in a Sample of Caucasian, Asian, and Pacific Islander Women. Archives of Women's Mental Health, 12, 393-400. http://dx.doi.org/10.1007/s00737-009-0087-0

Palmieri, P., Weathers, F., Difede, J., \& King, D. (2007). Confirmatory Factor Analysis of the PTSD Checklist and the Clinician-Administered PTSD Scale in Disaster Workers Exposed to the World Trade Center Ground Zero. Journal of Abnormal Psychology, 116, 329-341. http://dx.doi.org/10.1037/0021-843X.116.2.329

Parfitt, Y. M., \& Ayers, S. (2009). The Effect of Post-Natal Symptoms of Post-Traumatic Stress and Depression on the Couple's Relationship and Parent-Baby Bond. Journal of Reproductive and Infant Psychology, 27, 127-142. http://dx.doi.org/10.1080/02646830802350831

Pearlin, L. I., Aneshensel, C. S., \& Leblanc, A. J. (1997). The Forms and Mechanisms of Stress Proliferation: The Case of AIDS Caregivers. Journal of Health and Social Behavior, 38, 223-236. http://dx.doi.org/10.2307/2955368

Phillips, R. (2013). The Sacred Hour: Uninterrupted Skin-to-Skin Contact Immediately after Birth. Newborn and Infant Nursing Reviews, 13, 67-72. http://dx.doi.org/10.1053/j.nainr.2013.04.001

Quinn, J. J., Skipper, R. A., \& Claflin, D. I. (2013). Infant Stress Exposure Produces Persistent Enhancement of Fear Learning across Development. Developmental Psychobiology, 56, 1008-1016. http://dx.doi.org/10.1002/dev.21181 
Rank, O. (1924). Das Trauma der Geburt [The Trauma of Birth]. Translated into English 1929, Mineola, NY: Dover, 1994.

Richardson, R., \& Hayne, H. (2007). You Can’t Take It with You: The Translation of Memory across Development. Current Directions in Psychological Science, 16, 223-227. http://dx.doi.org/10.1111/j.1467-8721.2007.00508.x

Simcock, G., \& Hayne, H. (2002). Children Fail to Translate Their Preverbal Memories into Language. American Psychological Society, 13, 225-231.

Soet, J. E., Brack, G. A., \& DiIorio, C. (2003). Prevalence and Predictors of Women’s Experience of Psychological Trauma during Childbirth. Birth, 30, 36-46. http://dx.doi.org/10.1046/j.1523-536X.2003.00215.x

Wechsler, D. (2003). Wechsler Intelligence Scale for Children-Fourth Edition: Technical and Interpretive Manual. San Antonio, TX: The Psychological Corporation.

White, T., Matthey, S., Boyd, K., \& Barnett, B. (2006). Postnatal Depression and Post-Traumatic Stress after Childbirth: Prevalence, Course and Co-Occurrence. Journal of Reproductive and Infant Psychology, 24, 107-120.

http://dx.doi.org/10.1080/02646830600643874 